\title{
Co-integration Test: An Application to Selected Sorghum Markets in Sudan
}

\author{
Abda Abdalla Emam ${ }^{1}$, Nagat Ahmed Elmulthum ${ }^{1} \&$ Amal Saeed Abass ${ }^{1}$ \\ ${ }^{1}$ Department of Agri-business and Consumer Science, Faculty of Agriculture and Food Science, King Faisal \\ University, Saudi Arabia
}

Correspondence: Abda Abdalla Emam, Department of Agri-business and Consumer Science, Faculty of Agriculture and Food Science, King Faisal University, Saudi Arabia. E-mail: abdaemam@hotmail.com

Received: March 6, 2018

doi:10.5539/jas.v10n6p383
Accepted: April 8, $2018 \quad$ Online Published: May 15, 2018

URL: https://doi.org/10.5539/jas.v10n6p383

\begin{abstract}
An attempt was made in the study to understand the nature of the market integration. The study was based mainly on monthly wholesale price of sorghum in four market locations; namely Khartoum, Elobied, Gdarif and Damazin. Sorghum wholesale price series was used for the period from January 2012 to December 2016. Unit root test, Johnson co-integration test and Error Correction model were used to disclose stationary series, the long run relationship and short run relationship between these markets, respectively. The result showed that, long run relationship was indicated between all pairs of markets, except between Khartoum and Elobied market (consumption or deficit market). Long run equilibrium indicated adjustment to surplus markets (Gadarief and Damazin). This result may be interpreted by the fact that these markets are connected by good communication and transportation. From ECM model, Wholesale sorghum prices in all markets (higher price) quickly fall back towards Gadarif market whereas Gadarif adjusts back to Khartoum. Also, higher wholesale prices in Damazin quickly fall back towards all markets. There is short run causality running from: Gadarif and Damazin to Khartoum, Gadarif to Elobied and Khartoum to Damazin market. Long run equilibrium indicated adjustment to surplus markets (Gadarief and Damazin).This result may be reflected to good communication and transportation between the markets.
\end{abstract}

Keywords: sorghum, error correction model, market integration, Sudan

\section{Introduction}

Market integration refers to the extent to which events in one section of a market has an impact on events elsewhere in the same market (Emam \& Hassan, 2002). Integrated markets are defined as markets in which price of differentiated products do not behave independently (Monke \& Petzel, 1984). Two markets are co-integrated, if prices in one market adjust to the price shocks in the other market. This price correlation between markets may result from the run of goods from surplus to deficit areas (Jaleta \& Gebremedhin, 2012). Prefect market characters represents pre-requisite for market integration (Emam, 2001). Good communication and transportation between the markets may play a vital role in attaining market integration. Appropriate decision-making depend on reliable information on variable market condition, which is expressed by changing prices. Prices contain information crucial to maximize the returns to production and marketing investment. A farmer's planting decision depends on expected profits, where a trader in search of profit reads and translates price signals in decision. The accuracy, reliability and promptness of market information are therefore, critical in attaining pricing efficiency, which leads to market integration (Emam \& Hassan, 2002).

Generally in Sudan like other developing countries, news about price changes and related price forces in terminal markets are generally obtained from informal sources. Such information is subjected to inaccuracy, which results in pricing inefficiency. Several studies were conducted on market integration among them are the followings: Amassaib et al. (2015) investigated the integration between local and World prices of sorghum. In addition the transmission rate from international prices to local prices was measured. Results indicated short run and long run inelastic sorghum local prices in response to sorghum production cost and adjusted world prices. In addition, based on the results, the effects of adjusted international prices implied that the reduction of tariff rate and devaluation would lead to a rise in sorghum prices. Abdalla (2016) examined the relation between sorghum prices and integration of markets in Sudan. In addition, the presence or absence of causality between integrated 
markets was tested. Results indicated positive market co integration for the group of markets sharing peaceful region and connected with paved roads, indicating efficient marketing that facilitates policy implementation and long-term food security. The group of markets that suffers civil conflicts and inappropriate infrastructure showed market segmentation, indicating separate policy designs required for different markets. Sekhar (2012) aimed to assess the degree and extent of market integration in selected markets in India. The results indicated that the commodity markets, which do not face restrictions such as inter regional and interstate restrictions are well integrated such as edible oil and gram. In contrast, rice market which face interstate restrictions, does not show market integration at the national level.

Sorghum, millet and wheat are considered as stable food grain in Sudan. Sorghum is among food grains spread geographically in Sudan. In the northern States of Sudan, wheat is considered as the major food grain followed by sorghum, while in eastern and central Sudan sorghum is more dominant, whereas in western Sudan millet is the main food grain followed by sorghum (Abdalla, 2016). The main objective of the study was to measure the extent of market integration for sorghum in four market locations in Sudan, namely, Khartoum, Gadarif, Damazin and Elobied.

\section{Methods of Analysis}

\subsection{Study Area and Data Description}

The study depends mainly on secondary data. Monthly sorghum prices for the period extend from January 2012 to December 2016 were collected from Ministry of Agriculture and Forestry. Markets studied are Gadaref, Damazin, Khartoum and Elobied. Khartoum is a capital of Sudan and represents deficit market. Gadarif and Damazin are located in the biggest sorghum producer areas in Sudan (surplus) (Abdalla, 2016). Also, Gadarif is considered as bigger sorghum market in Sudan. Elobied market is considered as deficit market. The study relied mainly on secondary data, namely, Average wholesale price of sorghum in selected markets from January 2012 to December 2016.

\subsection{Unit Root Test}

The first step in testing co-integration is to test for the order of integration of the series. The series of commodity prices in different markets are tested for stationary. Several approaches are available for testing the existence of unit roots, among them is the Augmented Dickey Fuller (ADF) Test. The ADF test is based on the following regression equation:

$$
\Delta X_{t}=\alpha+B t+\Pi X_{t-1}+u_{t}
$$

Where, $t=$ time selected, $\alpha=$ intercept, $B=$ trend, $\Pi=Q-1, \Delta X_{t}=X_{t}-X_{t-1}$.

For testing stationary we either test for $\mathrm{H}_{0}: \Pi=0$ or $Q=1$. Against $\mathrm{H}_{1}: \Pi<0$ or $Q<1$.

Rejection of $\mathrm{H}_{0}$ when ADF statistic is greater than the critical $t$ value indicating the series is stationary

\subsection{Granger Causality Test}

Granger causality test how the lagged prices in one market might change prices in the other market (Granger, 1969; Engel \& Granger, 1987). Granger causality test can highlight the existence of potential causality and direction of causality among prices in different markets locations. Granger causality between two prices series of market $Y$ and $X$ is specified as:

$$
Y_{t}=\sum_{i=1}^{k} \alpha_{i 1} Y_{t-i}+\sum_{i=1}^{k} \beta_{i} X_{t-i}+\mu_{t 1}
$$

and,

$$
X_{t}=\sum_{i=1}^{k} \alpha_{i 2} X_{t-i}+\sum_{i=1}^{k} \tau_{i} Y_{t-i}+\mu_{t 2}
$$

Where, $k$ is the maximum number of lagged prices incorporated in the model. An F-statistic for testing "Granger-Causality" is given, for which the null hypotheses to be tested is $H_{0}: \beta_{1}=\beta_{2}=\ldots=\beta_{K}=0$. The calculated F-statistic is compared to critical F-value, rejection of null hypothesisfor a condition where price in market $X$ is expected to Granger cause price in market $Y$. Similarly, rejection the following $H_{0}: \tau_{1}=\tau_{2}=\ldots=\tau_{K}=$ 0 , once price in market $Y$ is estimated to Granger cause price in market $X$.

\subsection{Lag Specification}

The number of maximum lags to be included in the co-integration test is identified. There are a number of criteria that can be used in selecting the lag orders; Akaike Information Criterion (AIC) is the mainly widespread one. 


\subsection{Johansen Tests for Co-integration}

The Johansen test and estimation strategy (maximum likelihood) is used for estimating co-integrating vectors in case of more than two variables. The Johansen test gives estimates of the co-integrating vectors, first test the variables for not having unit roots. The vector auto regression model (VAR) express each variable as a linear function of past lags of itself and past lags of other variables. It is a stochastic process model used for capturing the linear independence between multiple time series which may be expressed by the following equation:

$$
\Delta X_{t}=\Pi X_{t-k}+\sum_{i=1}^{k-1} \Gamma_{i} \Delta X_{t-i}+u_{t}
$$

The matrix $\Pi$ could be written in terms of adjustment coefficients. If the matrix $\Pi=0$ then the variables are not co integrated. One way of doing the test is to test whether the rank of matrix $\Pi=0$. On the other hand if the variables are cointegrated, the rank $\Pi \neq 0$ and the rank $\Pi$ is equal to the number of co-integrating vectors. The number of co-integrating vectors is lower than or equal to the number of variables. However, if the rank is less than number of variables then the determinant is equal to 0 . To solve this problem eigenvalues are used. Johansen test is based on eigenvalues by transforming data to represent linear combinations of data that have max correlation. We used Johansen tests for testing co-integration, namely maximum eigenvalue and trace test. For both statistics, the null hypothesis of no integration is tested against the alternative of co integration. The two test differ in alternative hypothesis. The maximum eigenvalue tests the largest eigenvalue relative to the next largest value is 0 . The test statistics (the maximum remaining likelihood test) is given by the following equation:

$$
L R\left(r_{0}, r_{0}+1\right)=-T \ln \left(1-\Lambda_{r_{0}+1}\right)
$$

Where, $L R\left(r_{0}, r_{0}+1\right)$ is the likelihood ratio test statistic for testing whether rank $(I)=r_{0}$ versus the alternative hypothesis that rank $(\Pi)=r_{0}+1$. For example the hypothesis that rank $(I)=0$ against the hypothesis that rank $(I T)=1$ is tested by the statistic:

$$
L R(0,1)=-T \ln \left(1-\Lambda_{1}\right)
$$

The trace test is a test of whether the rank of the matrix $\Pi$ is $r_{0}$. Null hypothesis is rank $(\Pi)=r_{0}$, the alternative is $r_{0}<\operatorname{rank}(\Pi) \leq \mathrm{n}$, where $\mathrm{n}$ represent the maximum number of co-integrating vectors. However, if the first null hypothesis is rejected, the next null hypothesis is rank $(\Pi)=r_{0}+1$, where, the alternative is that $r_{0}+1<\operatorname{rank}(\Pi)$ $\leq \mathrm{n}$. The likelihood ratio test is given by the following equation:

$$
L R\left(r_{0}, n\right)=-T \sum_{i=r_{0}+1}^{n} \ln \left(1-\Lambda_{i}\right)
$$

Where, $L R\left(r_{0}, n\right)$ is the likelihood ratio to test whether, rank $(\Pi)=r$ against the hypothesis rank $(\Pi) \leq n$. For instant the hypothesis that rank $(\Pi)=0$ against the hypothesis that rank $(\Pi) \leq n$ is tested using the likelihood ratio statistic.

\subsection{Error Correction Model (ECM)}

$$
L R(0, n)=-T \sum_{i=1}^{n} \ln \left(1-\Lambda_{i}\right)
$$

Finally, short and long run equilibrium has been investigated with the help of error correction model (ECM) which is an appropriate system of single equation. The error correction model tells us the degree to which the equilibrium behavior drives short run dynamics. Equilibrium relationship in turn have implications for a short run behavior, one or more series move to restore equilibrium. Government support falls with poor economic conditions and improves in the economic booms, adversarial behavior is matched by increasingly confrontational responses increase in spending decreases in liberal policy preferences and period of sustained economic growth produces in party support. In each case, short run change is necessary to maintain the long run relationships (Boef, 2000). Short and long run equilibrium between the variable EC and FA in the system have been investigated with the help of $\mathrm{ECM}$ as given below.

$$
d(E C)=b_{3} d(F A)+b_{4} U_{t-1}+V
$$

Where, $d(E C)=$ first difference of electricity consumption; $d(F A)=$ first difference of foreign aid; $U_{t-1}=$ One period lag of residual obtained from the OLS estimation (Equation 1 ); $b_{3}$ and $b_{4}$ are parameters to be estimated; $V$ $=$ Error term.

Parameters $b_{3}$ irrespective of its sign but should be individually significant represent short run equilibrium between $E C$ and $F A$. However, parameter $b_{4}$ represents long run equilibrium between the same variable. The sign of $b_{4}$ should be negative and significant as well for holding long run equilibrium. 


\section{Spatial Analysis Result and Discussion}

\subsection{The Result of a Unit Root Tests}

Table 1 shows the results of a unit root test for prices series in different market locations. After first difference, $\mathrm{ADF}$ statistics are greater than the critical t-values at $1 \%$ level of significance. Accordingly, the null hypothesis of a unit root was rejected. The conclusion is that all the series are 1(1) and stationary.

Table 1. Augmented Dickey Fuller (ADF) unit root test

\begin{tabular}{llc}
\hline Time series & \multicolumn{2}{c}{ ADF statistic } \\
\cline { 2 - 3 }$\left(1^{\text {st }}\right.$ difference $)$ & Intercept and trend & Intercept \\
\hline Khartoum & $-9.961980^{*}$ & $-9.992121^{*}$ \\
Elobied & $-6.877102^{*}$ & $-6.841700^{*}$ \\
Gadarif & $-4.171037^{*}$ & $-4.191017^{*}$ \\
Damazin & $-6.398076^{*}$ & $-6.416672^{*}$ \\
\hline
\end{tabular}

Note. ${ }^{*}$ Critical value at $1 \%$ level of significance.

Source: Data was collected and calculated.

\subsection{Engle-Granger Causality Test (Weak Exogeneity)}

The Engle-Granger causality test could provide some indication for the existence of cause and effect relationships between wholesale prices of sorghum in different markets locations. Table 2 shows Granger Causality test results, only the significant F-values are presented. Stronger causality relatively was shown on sorghum wholesale prices in Khartoum from Elobied, Gadarif and Damazin market which were presented by $\mathrm{F}$ value $=10.988,5.713$ and 7.315 at $1 \%$ level of significant, respectively. Wholesale prices in Elobied market was Granger caused by Khartoum and Damazin wholesale prices ( $F=4.0337$ and 3.428 at $5 \%$ level of significance). Also, sorghum wholesale price in Gadarif market was Granger caused by wholesale prices of all markets at $1 \%$ level of significant this results was assured by Abdalla (2016) who recorded that Gadaref past and present sorghum prices can help in predicting future sorghum prices in Om Durman, Damazin, Sennar and Rabak sorghum prices. Wholesale prices of sorghum in Damazin market was Granger caused by Khartoum with F value $=4.672$ at $5 \%$ level of significant.

Table 2. Granger causality (F-statistic) test results

\begin{tabular}{lllll}
\hline Variable & Khartoum & Elobied & Gadarif & Damazin \\
\hline Khartoum & & $10.988^{*}$ & $5.713^{*}$ & $7.315^{*}$ \\
Elobied & $4.037^{* *}$ & & - & $3.428^{* *}$ \\
Gadarif & $6.379^{*}$ & $11.222^{*}$ & & $15.962^{*}$ \\
Damazin & $4.672^{* *}$ & - & - & \\
\hline
\end{tabular}

Note. ${ }^{*}$ and $* *$ critical value at $1 \%$ and $5 \%$ level of significance, respectively.

Source: Data was collected and calculated.

\subsection{Results of Co-integration Test}

Before conducting the co-integration test, lag length must be specified for any pairs of wholesale price series.

All whosale prices series are of the same order 1(1) as obtainable by ADF test which allow to estimate the co-integration test to reveal the long run relationship. Table 3 below shows the Johansen co-integration test results for any pair markets.

\subsubsection{Khartoum and Elobied}

The Table shows co-integration results between Khartoum and Elobied prices series. The calculated trace statistics (10.301 and 2.546) were less than critical value at 5\% and $1 \%$ level of significant. The same result was obtained by Max-Eigen statistic. Max-Eigen statistic (7.755 and 2.546) is less than critical value at $5 \%$ and $1 \%$ level of significant. The null hypothesizes were accepted concluding that no co-integration between prices series. This result may be explained by fact that Khartoum and Elobied are deficit or consumption areas. 
Table 3. Results of co-integration test

\begin{tabular}{|c|c|c|c|c|c|}
\hline & & Trace Statistic & Max Eigenvalue Statistic & Trace Statistic & Max Eigenevalue Statistic \\
\hline & & \multicolumn{2}{|c|}{ Khartoum-Elobied } & \multicolumn{2}{|c|}{ Khartoum-Gadarif } \\
\hline $\mathrm{H}_{0}$ & $\mathrm{H}_{1}$ & \multicolumn{2}{|c|}{ Lags interval (in first differences): 1 to 5} & \multicolumn{2}{|c|}{ Lags interval (in first differences): 1 to 1} \\
\hline $\mathrm{r}=0$ & $\mathrm{r}=1$ & 10.301 & 7.755 & $22.111 *$ & $19.484 *$ \\
\hline \multirow[t]{2}{*}{$\mathrm{r}=1$} & $\mathrm{r}=2$ & 02.546 & 02.546 & 02.626 & 02.626 \\
\hline & & \multicolumn{2}{|c|}{ Khartoum-Damazin } & \multicolumn{2}{|c|}{ Elobied-Gadarif } \\
\hline $\mathrm{H}_{0}$ & $\mathrm{H}_{1}$ & \multicolumn{2}{|c|}{ Lags interval (in first differences): 1 to 2} & \multicolumn{2}{|c|}{ Lags interval (in first differences) 1 to 3} \\
\hline $\mathrm{r}=0$ & $\mathrm{r}=1$ & $15.92172 * *$ & 12.45378 & $16.11234 * *$ & 25.15596 \\
\hline \multirow[t]{2}{*}{$\mathrm{r}=1$} & $\mathrm{r}=2$ & 03.467938 & 03.467938 & 2.374064 & 03.90251 \\
\hline & & \multicolumn{2}{|c|}{ Elobied-Damazin } & \multicolumn{2}{|c|}{ Gadarif-Damazin } \\
\hline $\mathrm{H}_{0}$ & $\mathrm{H}_{1}$ & \multicolumn{2}{|c|}{ Lags interval (in first differences): 1 to 1} & \multicolumn{2}{|c|}{ Lags interval (in first differences): 1 to 3} \\
\hline $\mathrm{r}=0$ & $\mathrm{r}=1$ & $29.05881 *$ & $25.15596^{*}$ & $16.82824 *$ & $15.64402 *$ \\
\hline $\mathrm{r}=1$ & $\mathrm{r}=2$ & $03.902851 * *$ & $03.90251 * *$ & 01.184020 & 01.184020 \\
\hline
\end{tabular}

Note. ${ }^{*}(*)$ denotes rejection of the hypothesis at $1 \%$ and $5 \%$, respectively.

Source: Data was collected and calculated.

\subsubsection{Khartoum and Gadarif}

The Table records co-integration results between Khartoum and Gadarif prices series. The calculated trace statistics (22.111) was more than critical at $1 \%$ level of significant. The same result was obtained by Max-Eigen statistic. Max-Eigen statistic (19.484) was more than critical value at $1 \%$ level of significant. The null hypothesis was rejected, concluding that the existence of co-integration between two prices series representing by 1 co-integration equation.

\subsubsection{Khartoum and Damazin}

Co-integration results were noticed between Khartoum and Damazin prices series (Table 3). The calculated tract statistic (15.92172) was more than critical value at 5\% level of significant. Max-Eigen statistic (12.45378) is less than critical value at $5 \%$ and $1 \%$ level of significant. The null hypothesis was rejected concluding co-integration between prices series is present.

\subsubsection{Elobied and Gadarif}

Co-integration results between Elobied and Gadrif prices series were shown in the Table. The calculated trace statistic (16.11234) was more than critical value at $5 \%$ level of significant. Max-Eigen statistic (2.374064) is less than critical value at $5 \%$ and $1 \%$ level of significant. The null hypothesis was rejected concluding co-integration between prices series. Elobied and Gadarif show observable co-integration meaning that there is a long-run relationship.

\subsubsection{Elobied and Damazin}

Table 3 shows co-integration results between Elobied and Damazin prices series. The calculated trace statistics (29.05881 and 3.90251) were more than critical value at 5\% level of significant. Max-Eigen statistics (25.15596 and 3.90251) were more than critical value at 5\% level of significant. The null hypothesis was rejected concluding that co-integration between prices series is shown. Trace test and Max-Eigen test indicate 2 and 1co-integrating equations at 5\% level and 1\% level of significant, respectively. From above results, Elobied and Damazin show evidence of con-integration during study period.

\subsubsection{Gadarif and Damazin}

The Table records that the calculated trace statistic (16.82824) was more than critical value at $5 \%$ level of significant. Max-Eigen statistic (15.64402) is more than critical value at $5 \%$ level of significant. The null hypothesis was rejected. The long-run relationship between prices series is noticed.

\subsection{Results of ECM}

Table 3 records the results of Johansen's co-integration test. From the results, there are long term co-integration relationship between any pair of markets price series, except between Khartoum and Elobied market. ECM estimates disclose the direction of causalities and adjustments completed between pair markets when there are price shocks. Table 4 records the adjustment parameter for pair markets. The ECM coefficients (negative and 
significant) show how one market adjusts to the long-run equilibrium. From the Table, Wholesale sorghum prices in all markets (higher price) quickly fall back towards Gadarif market, being a highly surplus market, whereas Gadarif adjusts back to Khartoum, since ECM coefficients are negative and significant. Higher wholesale prices in Khartoum, Elobied and Gadarif quickly fall back towards Damazin market, being a surplus market. This result was supported by Alaxander and Wyeth (1994) whose results indicated that, in driving prices, supply sources are of higher importance as compared to demand sources.

Table 4. Error Correction Model estimates (adjustment parameters)

\begin{tabular}{|c|c|c|c|c|}
\hline \multirow{2}{*}{ Variable (dependent) } & \multicolumn{4}{|c|}{ Adjusting to (independent) } \\
\hline & Khartoum & Elobied & Gadarif & Damazin \\
\hline Khartoum & & - & $-0.385[-2.227]$ & $0.123[0.914]$ \\
\hline Elobied & - & & $-0.847[-4.729]$ & $-0.059[-0322]$ \\
\hline Gadarif & $-0.412[-3.021]$ & $-0.030[0.156]$ & & $0.461[2.258]$ \\
\hline Damazin & $-0.503[-3.47]$ & $-0.684[-3.052]$ & $-0.957[-3.933]$ & \\
\hline
\end{tabular}

Source: Data was collected and calculated. Figures in parenthesis are critical t-value.

Table 5 discloses short run causality from independent to dependent market. The sign of the coefficients will be revised at interpretation. From the Table, There is short run causality running from: Gadarif and Damazin to Khartoum, Gadarif to Elobied and Khartoum to Damazin market. Also, the result shows that Khartoum prices reduce by $30.2 \%$ and $55.4 \%$ per month when prices changed in Gadarif and Damazin by 1 unit currency, respectively (Table 5). Elobied prices increase by $27 \%$ each month when Gadarif prices changed by one unit currency, this result is contrary to the theory, it may be reflected to the fact that Elobied is millet consuming area rather than sorghum. Damazin prices increase by $22 \%$ during month when Khartoum prices changed by one unit currency.

Table 5. Error Correction Model estimates (short-run causality)

\begin{tabular}{|c|c|c|c|c|}
\hline \multirow{2}{*}{ Variable (dependent) } & \multicolumn{4}{|c|}{ Adjusting to (independent) } \\
\hline & Khartoum & Elobied & Gadarif & Damazin \\
\hline Khartoum & & - & $0.302[1.758]$ & $0.554[2.775]$ \\
\hline Elobied & - & & $-0.267[-1.516]$ & $0.176[0.745]$ \\
\hline Gadarif & $0.065[-0.562]$ & $0.184[1.220]$ & & $0.278[1.085]$ \\
\hline Damazin & $-0.219[-1.507]$ & $-0.117[-0.639]$ & $0.073[0.290]$ & \\
\hline
\end{tabular}

Source: Data was collected and calculated. Figures in parenthesis are critical t-value.

\section{Conclusion}

Market co-integration test was conducted for four sorghum markets locations. All pairs of markets detected long run relation (co-integration), except Khartoum and Elobied (the two markets are deficit). This result may be interpreted by the fact that these markets are connected by good communication and transportation. Long run equilibrium indicated adjustment to surplus markets (Gadarief and Damazin).

\section{Reference}

Abdalla, A. M. (2016). Sorghum Prices and Markets Integration in Sudan. Int. J. Econ. Manag. Sci., 5, 363. https://doi.org/10.4172/2162-6359.1000363

Alexander, C., \& Wyeth, J. (1994). Co-integration and market integration: An application to the Indonesian rice market. The Journal of Development Studies, 30(2), 330-334. https://doi.org/10.1080/00220389408422317

Amassaib, M. A., Elawad, S. M., ElNaim, A. M., \& Elkhiedi, E. E. (2015). Domestic Price Formation of Sorghum under Export Policies in Sudan. American Journal of Marketing Research, 1(2), 66-69. https://doi.org/10.18551/rjoas.2015-07.02

Dhungel, K. R. (2014). Estimation of Short and Long Run Equilibrium Coefficients in Error Correction Model: An Empirical Evidence from Nepal. International Journal of Econometrics and Financial Management, 2(6), 214-219. 
Emam, A. A. (2002). Agricultural Marketing. Ministry of Education, Khartoum, Sudan.

Emam, A. A., \& Hassan, K. I. (2002). Co-integration and market integration: An application to millet market in Darfur States, Sudan. J. Agri. Sci., 10(2). Retrieved from http://41.67.20.41/handle/123456789/2081

Engle, R. F., \& Granger, C. W. (1987). Co-integration and error correction: Representation, estimation and testing. Econometrica, 55, 251-276. https://doi.org/10.2307/1913236

Granger, C. W. J. (1969). Investigating Causal Relations by Econometric Models and Cross-Spectral Methods. Econometrica, 37, 424-438. https://doi.org/10.2307/1912791

Jaleta, M., \& Gebremedhin, B. (2012). Price co-integration analyses of food crop markets: The case of wheat and teff commodities in Northern Ethiopia. African Journal of Agricultural Research, 7(25), 3643-3652.

Johansen, S. (1988). Statistical Analysis of Co-integrating vectors. Journal of Economic Dynamics and Control 12, 231-254. https://doi.org/10.1016/0165-1889(88)90041-3

Johansen, S. (1991). Estimation and Hypothesis testing co-integration vectors in Gaussian vector Autoregressive models. Econometric, 59, 1551-1580. https://doi.org/10.2307/2938278

Monke, E., \& Petzel, T. (1984). Market integration: An application to international trade in cotton. American Journal of Agricultural Economics, 66(4), 481-487. https://doi.org/10.2307/1240927

Regasa, D., \& Zemedu, L. (2015). Onion market integration: The case of Harar, DireDawa and Central Markets. Journal of Agricultural Economics and Development, 4(2), 021-029.

Sekhar, C. S. (2012). Agricultural market integration in India: An analysis of select commodities. Food Policy, 37(3), 309-322. https://doi.org/10.1016/j.foodpol.2012.03.002

\section{Copyrights}

Copyright for this article is retained by the author(s), with first publication rights granted to the journal.

This is an open-access article distributed under the terms and conditions of the Creative Commons Attribution license (http://creativecommons.org/licenses/by/4.0/). 